Syntax Literate : Jurnal Ilmiah Indonesia p-ISSN: 2541-0849 e-ISSN: 2548-1398

Vol. 5, No. 5 Mei 2020

\title{
PENGARUH DANA PIHAK KETIGA, MODAL BANK, JUMLAH KANTOR CABANG, TINGKAT SUKU BUNGA DAN JUMLAH UANG BEREDAR TERHADAP JUMLAH KREDIT UMKM BANK BUMN
}

\section{Ade Onny Siagian}

Fakultas Ekonomi dan Bisnis Universitas Bina Sarana Informatika

Email: adegiant78@gmail.com

\section{Abstract}

The purpose of this research is to study and analyze the influence of third party funds, bank capital, number of branch offices, interest rates and money supply to the number of MSME credit of BUMN banks and their implications for gross domestic product and unemployment rate. The research was carried out 9 months from April to November 2017 including design, conduct and report the results of the research. The results of this study indicate that the factors of third party funds, bank capital, number of branch offices, interest rates and the money supply simultaneously have a significant effect on the number of MSME credit of BUMN banks. Partially third party funds, the number of branch offices and the money supply have a significant and positive effect on the number of BUMN MSME loans, while capital and interest rates have a significant and negative effect on MSME bank BUMN loans with the least squares regression $Y=6942,054-0.402009+$ 44.134081-10.828790 +39.023116. BUMN MSME credit has a significant positive effect on gross domestic product with a regression of $Y=1274014+5.542533$ and a significant negative effect on the unemployment rate with a regression of $Y=$ 825.6549-0.00795. the government as the majority owner of a state-owned bank in addition to dividend income, social responsibility responsiveness, but for the government more to the multiplayer effect of an increase in the number of MSME loans BUMN banks have an impact on increasing gross domestic product and decreasing the unemployment rate, which will ultimately have an impact on increasing tax revenue, growth economy, and decreasing the poor through the expansion and expansion of business, employment opportunities in micro, small and medium scale businesses will become major entrepreneurs and host in their own country in the future, able to compete with the ASEAN economic community $(A E C)$.

Keywords: Stock Price Volatility, Dividend Payout Ratio, Leverage Firm Size, Trading Volume, Earning Volatility, and Inflation.

\section{Abstrak}

Tujuan dari penelitian ini adalah untuk mengkaji dan menganalisis pengaruh dana pihak ketiga, modal bank, jumlah kantor cabang, tingkat suku bunga dan jumlah uang beredar terhadap jumlah kredit UMKM bank BUMN dan implikasinya 
terhadap produk domestik bruto dan tingkat pengangguran. Pelaksanaan penelitian ini dilaksanakan 9 bulan sejak april sampai dengan november 2017 juga termasuk didalamnya merancang, melaksanakan dan melaporkan hasil penelitian. Penelitian ini menggunakan data sekunder yaitu data panel yakni gabungan time series dan cross section bank badan usaha milik negara (BUMN) dijadikan penelitian selama 11 tahun dari tahun 2006 sampai dengan 2016. Metode yang digunakan adalah explanatory research untuk menjelaskan hubungan kasual antar variabel yang diteliti dalam suatu model, melalui pengujian hipotesis. Teknik analisis yang digunakan adalah regresi linier berganda dan regresi linier sederhana. Hasil penelitian ini menunjukkan bahwa faktor dana pihak ketiga, modal bank, jumlah kantor cabang, tingkat suku bunga dan jumlah uang beredar secara simultan berpengaruh signifikan terhadap jumlah kredit UMKM bank BUMN. Secara parsial dana pihak ketiga, jumlah kantor cabang dan jumlah uang beredar berpengaruh signifikan dan positif terhadap jumlah kredit UMKM BUMN, sedangkan modal dan tingkat bunga berpengaruh signifikan dan negatif terhadap kredit UMKM bank BUMN dengan regresi least squares $\mathrm{Y}=6942.054$ $0.402009+44.134081-10.828790+39.023116$. jumlah kredit UMKM BUMN berpengaruh signifikan positif terhdap produk domestik bruto dengan regresi $\mathrm{Y}=$ $1274014+5.542533$ dan berpengaruh signifikan negatif terhadap tingkat pengangguran dengan regresi $\mathrm{Y}=825.6549-0.00795$. pemerintah sebagai pemilik mayoritas bank BUMN disamping pendapatan deviden, conporate social responcibility, tetapi bagi pemerintah lebih kepada multiplayer effect dari peningkatan jumlah kredit UMKM bank BUMN berdampak pada peningkatan produk domestik bruto dan penurunan tingkat pengangguran, yang pada akhirnya akan berdampak pada peningkatan penerimaan pajak, pertumbuhan ekonomi, dan berkurang orang miskin melalui pertambahan dan perluasan usaha, kesempatan kerja di udaha mikro, kecil dan menengah naik kelas menjadi pengusaha besar dan menjadi tuan rumah di negeri sendiri pada masa yang akan datang, mampu bersaing dengan masyarakat ekonomi asean (MEA).

Kata kunci: Volatilitas Harga Saham, Rasio Pembagian Deviden, Pengaruh Ukuran Perusahaan, Volume Perdagangan, Volatilitas Pendapatan Dan Inflansi

\section{Pendahuluan}

Bangsa Indonesia sudah merdeka lebih dari 73 tahun, yang kaya raya atas: alam, fauna, bahasa, budaya, kearifan lokal dan berbagai sumber lainnya. Indonesia sebagai negara maritim, Indonesia juga harus memiliki kedaulatan didepan negara lain sebagai bentuk pengakuan atas keberadaan dan kepemilikan sumber daya yang dimiliki (Simarmata, 2017). Akan tetapi masih jauh dari cita-cita kemerdekaan Indonesia sebagaimana dicantumkan dalam undang-undang dasar 1945 menuju masyarakat adil makmur serta pasal 27 ayat (2) menyatakan bahwa: tiap-tiap warga negara berhak atas pekerjaan dan penghidupan yang layak bagi kemanusiaan.

Tingkat pendapatan rata-rata penduduk Indonesia masih tergolong rendah mengakibatkan akumulasi modal atatu tabungan menjadi rendah;akibatnya pertumbuhan investasi menjadi rendah karena akumulasi modal yang rendah untuk pembukaan usaha baru atau ekspansi usaha menjadi rendah pula terutama para 
pengusaha mikro kecil dan menengah (UMKM). Kebutuhan modal usaha mikro kecil dan menengah diharapkan melalui fasilitas kredit perbankan. Guna menciptkan lapangan usaha baru, erat kaitannya dengan fakta atau hasil penelitian kementerian koperasi dan UMKM BPS 2015 yang pada intinya menyatakan bahwa: faktor penghambat usaha mikro, kecil dan menengah secara berurutan adalah pemodalah sebesar $51,09 \%$, pemasaran $34,72 \%$, bahan baku $8,59 \%$, ketenagakerjaan $1,09 \%$, distribusi transportasi $0,22 \%$ dan lain-lain 3,93\%. sebagaimana dapat dilihat diagram pie berikut (Manihuruk, 2018) dan dapat dilihat pada gambar berikut.

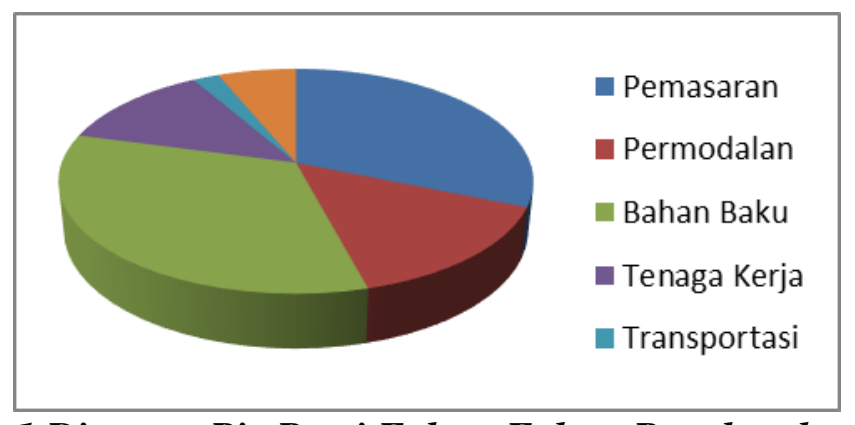

\section{Gambar 1 Diagram Pie Porsi Faktor Faktor Penghambat UMKM}

Dilihat dari jumlah penduduk Indonesia merupakan urutan keempat jumlah penduduk terbanyak didunia, sekaligus merupkan pangsa pasar perbankan finansial mandiri terbesar di dunia, namun memiliki lembaga keuangan komersial terkecil dalam ukuran, ragam, volume dan penetrasi pasar lamban dimana jumlah UMKM yang terdaftar di Indonesia masih kurang dari 30\% dari total UMKM, sementara di filipina dan vietnam masing-masing 87 dan 98\% (Hudson, Williams, Orviska, \& Nadin, 2012). Hasil survei ini masih valid adapun realisasinya pada saat ini tidak jauh berbeda.

Pembangunan nasional indonesia untuk mengejar ketertinggalan dan penerapan menghadapi persaingan dengan masyarakat ekonomi asean (MEA) melalui pembangunan ekonomi dari sektor ekonomi makro dan moneter, diperlukan: menciptakan ekspansi usaha dan produksi yang tinggi melalui pemberian fasilitas kredit perbankan, yang didukung oleh dana pihak ketiga, modal bank, jumlah kantor cabang bank yang tersebar diseluruh wilayah Indonesia, tingkat bunga yang bersaing dan jumlah uang beredar yang cukup sehingga roda perekonomian berputar dengan baik, pada akhirnya akan meningkatkan produk domestik bruto dan penurunan tingkat pengangguran.

Ash center harvard Kennedy school tahun 2010 menyatakan bahwa kebijakan khusus untuk mencapai transformasi di Indonesia. "the sum is greater than the parts" menggandakan kemakmuran bersama di Indonesia melalui integrasi lokal dan global (Nye, 2013) membahas tujuan utama pembangunan pemerintah Indonesia, yaitu bergabung dengan jajaran negara berpenghasilan menengah ke atas pada tahun 2025 . Penulis laporan tersebut berpendapat bahwa kebijakan saat ini akan tetap mencapai tujuan ini tetapi mungkin Indonesia akan gagal dalam tiga dimensi mendasar: pertumbuhan akan menjadi pengangguran, daya saing akan menurun, dan tidaksetaraan 
akan meningkat. Hal ini terjadi karena indonesia tidak maksimal memanfaatkan manfaat dari sebuah negara besar maupun keunggulan komparatif dinamis internasionalnya. Ash center mencatat bahwa walaupun temuan ini mengecewakan, analisis menyampaikan pandangan optimis bahwa rekomendasi tujuan tersebut akan dapat dicapai, dalam lanskap politik yang menantang saat ini. Penulis menegaskan bahwa Indonesia harus memilih tiga jalur pembangunan masa depan: reaktif, proaktif, dan transformatif. Tantangan utamanya adalah dengan serius mengejar reformasi ekonomi yang kuat dan berkelanjutan untuk kepentingan seluruh populasi daripada individu tertentu atau kelompok tertentu. Menurut (Meier, Barrowclough, \& Donmall, 2005) menyatakan bahwa bagaimanapun tabungan dan investas adalah kekuatan utama untuk pertumbuhan. Pendapatan nasional yang dibelanjakan untuk barang-barang konsumsi dan seberapa besar untuk pembentukan modal. Konsumsi masih perlu ditingkatkan karena sebagian besar masyarakat Indonesia masih hidup dalam tingkat subsistensi, pembentukan kapital juga perlu untuk meningkatkan produksi barang-barang konsumsi di masa depan. Jumlah modal bank BUMN trendnya meningkat, tahun 2005 sebesar Rp.49.490 juta terus meningkat menjadi Rp 399.257 juta pada tahun 2016. Dalam tahun 2010 terjadi pertumbuhan modal bank BUMN yang sangat besar 47,45\% dan pada tahun 2016 bertumbuh cukup besar 22,01\%.

Diketahui bahwa CAR bank BUMN, bank umum swasta nasional (BUSN) dan bank pembangunan daerah (BPD) dalam 11 tahun terakhir seluruh bank CAR diatas $8 \%$ atau seluruh bank sehat. Bank BUMN terendah 13,81\% tahun 2009 dan tertinggi tahun 2006 sebesar 21,20\% BUSN paling rendah 14,82\% tahun 2008 tertinggi 19,84\% tahun 2006, demikian juga BPD paling rendah 14,33\% tahun 2011 dan CAR tertinggi 19,24\% tahun 2005. CAR yang lebih tinggi menunjukkan bahwa telah terjadi ideal modal atau pengelolaan modal belum optimal atau kurang efektif dan kurang efisien. Dana pihak ketiga tahun 2005 semula Rp. 392.385 juta terus naik menjadi Rp. 1.943 .718 juta pada tahun 2016 dan dari ketiga jenis dana tersebut yang terbesar tabungan, deposito dan giro. Tingkat pertumbuhan 11 tahun berakhir cenderung stabil dari paling kecil 8,92\% tahun 2011 yang tertinggi 23,40\% tahun 2016. Jumlah kantor cabang bank BUMN jumlahnya terus meningkat pada tahun 2005 jumlah seluruh cabang bank BUMN sebanayak 7.131 unit dan tahun 2016 menjadi 20.390 unit layanan UMKM. Jumlah kantor cabang bank BUMN dalam lima tahun terakhir terjadi penurunan dari $13,97 \%$ tahun 2012 turun menjadi 3,18\% pada tahun 2016.

Tingkat suku bunga SBI tahun 2005 adalah 12,75\% dan pada tahun 2016 turun menjadi 4,75\%. Adapun selisih bunga simpanan dengan bunga kredit terkecil 2,96\% tahun 2005 dan tertinggi 7,13\% tahun 2009 dan pada tahun 2016 sebesar 6,11\%. Jumlah uang beredar terus meningkat Rp. 1.203 milyar pada tahun 2005 trendnya terus naik menjadi Rp. 5.345 milyar pada tahun 2016. Dilihat dari presentase pertumbuhan dalam lima tahun terakhir terjadi perlambatan dari $21,05 \%$ tahun 2012 terus menurun menjadi 11,63\% tahun 2016. 


\section{Tabel 1 \\ Jumlah Kredit dan Kredit UMKM bank BUMN tahun 2006-2016 (jutaan rupiah)}

\begin{tabular}{cccc}
\hline Tahun & Kredit bank BUMN & Kredit UMKM & $\begin{array}{c}\text { Presentasi kredit } \\
\text { UMKM }\end{array}$ \\
\hline 2006 & 281.143 & 204.180 & 72.62 \\
\hline 2007 & 344.317 & 263.414 & 76.50 \\
\hline 2008 & 458.021 & 308.551 & 67.37 \\
\hline 2009 & 533.945 & 355.892 & 66.65 \\
\hline 2010 & 630.148 & 434.217 & 68.91 \\
\hline 2011 & 761.373 & 485.342 & 63.75 \\
\hline 2012 & 942.253 & 559.825 & 59.41 \\
\hline 2013 & 1.156 .147 & 635.530 & 54.96 \\
\hline 2014 & 1.289 .773 & 707.562 & 54.85 \\
\hline 2015 & 1.487 .454 & 787.699 & 52.95 \\
\hline 2016 & 1.701 .786 & 868.168 & 51.01 \\
\hline
\end{tabular}

Fasilitas kredit bank BUMN trendnya terus naik pada tahun 2006 Rp. 281.143 juta terus naik menjadi Rp. 1.701.786 juta. Kredit UMKM pada tahun 2006 Rp. 204.180 juta terus meningkat menjadi Rp. 868.168 juta; namun secara presentasi terdapat penurunan dari 72,62\% pada tahun 2006 trendnya terus turun menjadi 51,01\% pada tahun 2016. Jumlah produk domestik bruto secara nominal rupaiah terus meningkat dimana tahun 2006 Rp. 3.338.193 juta dan tahun 2016 menjadi Rp. 12.406.809 juta. Hal ini menunjukkan bahwa proses pembangunan di Indonesia berhasil dengan baik yang berdampak peningkatan produk domestik bruto, namun dalam tahun 2010 terjadi penurunan sebesar $19,76 \%$ dan dalam lima tahun terakhir terjadi pelambatan pertumbuhan dari 10,01\% tahun 2012 turun menjadi 7,50\% tahun 2016.

Tabel 2

Perkembangan Produk Domestik Bruto tahun 2006-2016 (jutaan rupiah)

\begin{tabular}{cccc}
\hline Tahun & Produk domestik bruto & pertumbuhan & \% pertumbuhan \\
\hline 2006 & 3.338 .193 & 0 & 0 \\
\hline 2007 & 3.957 .403 & 619.210 & 18.54 \\
\hline 2008 & 5.354 .595 & 1.397 .192 & 35.30 \\
\hline 2009 & 6.971 .749 & 1.617 .154 & 30.20 \\
\hline 2010 & 5.593 .703 & -1.378 .046 & -19.76 \\
\hline 2011 & 7.831 .725 & 2.238 .022 & 40.01 \\
\hline 2012 & 8.615 .702 & 783.977 & 10.01 \\
\hline 2013 & 9.524 .735 & 909.033 & 10.55 \\
\hline 2014 & 10.565 .816 & 1.041 .081 & 10.93 \\
\hline 2015 & 11.540 .789 & 974.973 & 9.22 \\
\hline 2016 & 12.406 .809 & 866.020 & 7.50 \\
\hline
\end{tabular}


Semakin maju dan makmur suatu negara ditandai dengan menurunnya tingkat pengangguran. Persentase tingkat pengangguran di indonesia dalam 12 tahun terakhir cenderung menurun, pda tahun 2006 tingkat pengangguran $10.45 \%$ secara kuantitatif terus menurun hingga tahun 2016 menjadi 5.33\%. turunnya tingkat pengangguran tersebut membuktikan bahwa proses pembangunan Indonesia berhasil dengan baik. Lima tahun terakhir terjadi pelambatan pertumbuhan tingkat pengangguran tahun 2012 turun sebesar $1,1 \%$ terus cenderung menurun hingga tahun 2016 turun hanya $0.48 \%$.

Tabel 3

Tingkat Pengangguran

tahun 2006-2016

\begin{tabular}{c|c|c}
\hline Tahun & Tingkat pengangguran & Pertumbuhan tingkat pengangguran \\
\hline 2006 & $10,45 \%$ & - \\
\hline 2007 & $9,11 \%$ & $(1,34)$ \\
\hline 2008 & $8,39 \%$ & $(0.72)$ \\
\hline 2009 & $8,14 \%$ & $(0,25)$ \\
\hline 2010 & $7,41 \%$ & $0,73)$ \\
\hline 2011 & $7,48 \%$ & $(1,11)$ \\
\hline 2012 & $6,37 \%$ & 0,33 \\
\hline 2013 & $6,70 \%$ & $(0,76)$ \\
\hline 2014 & $5,94 \%$ & $(0,13)$ \\
\hline 2015 & $5,81 \%$ & $(0,48)$ \\
\hline 2016 & $5,33 \%$ &
\end{tabular}

Sumber data BPS

\section{Metode Penelitian}

Penelitian ini menggunakan pendekatan kuantitatif. Sumber data penelitian diperoleh dari instansi/lembaga seperti: Badan pusat statistik (BPS), Bank Indonesia, kementerian koperasi dan usaha kecil dan menengah, Lembaga pengetahuan Indonesia (LPI) dan Bank BUMN.

Dalam penelitian ini populasi adalah semua data variabel modal bank, dana pihak ketiga, jumlah kantor cabang, jumlah kredit bank BUMN, produk domestik bruto sebelum tahun 2006 sampai dengan tahun 2016. Data sampel yang digunakan adalah data triwulanan kedelapan variabel dimaksud dari tahun 2006 sampai dengan tahun 2016 (11 tahun).

Teknik analisis data yang digunakan menggunakan statistik inferensial, Uji normalitas, uji heteroskedasitas, uji autokolerasi dan uji multikolinieritas, uji t dan uji F.

\section{Hasil dan Pembahasan}

\section{A. Hasil}

Setelah dilakukan pengujian dari common effect, fixed effect dan random dan uji hausman test maka rekresi yang terbaik adalah random efect. 
1. Regresi panel least squares random effect

\section{Tabel 4}

Regresi panel least squares random effect

\begin{tabular}{|c|c|c|c|c|}
\hline \multicolumn{5}{|c|}{ Dependent variabel: Y? } \\
\hline \multicolumn{5}{|c|}{ Method: pooled EGLS (cross-section random effects) } \\
\hline \multicolumn{5}{|c|}{ Date: $01 / 17 / 19$ time: $22: 14$} \\
\hline \multicolumn{5}{|c|}{ Sample (adjusted): 144} \\
\hline \multicolumn{5}{|c|}{ Included observations: 44 after adjustments } \\
\hline \multicolumn{5}{|c|}{ Cross-section included: 4} \\
\hline \multicolumn{5}{|c|}{ Total pool (balanced) observations: 176} \\
\hline \multicolumn{5}{|c|}{ Swamy and arora estimator of component variances } \\
\hline variable & Coefficient & Std. error & t-statistic & Prob. \\
\hline $\mathrm{C}$ & 6942.054 & 3844.736 & 2.376643 & 0.0190 \\
\hline $\mathrm{X} 1 ?$ & -0.402009 & 0.176393 & -2.279053 & 0.0243 \\
\hline $\mathrm{X} 2 ?$ & 0.610616 & 0.043380 & 14.07599 & 0.0000 \\
\hline $\mathrm{X} 3 ?$ & 44.13408 & 5.458988 & 8.084664 & 0.0000 \\
\hline $\mathrm{X} 4 ?$ & -10.82879 & 4.306476 & -2.514536 & 0.0131 \\
\hline X5? & 39.023116 & 3.656454 & 10.67239 & 0.0000 \\
\hline \multicolumn{5}{|l|}{ Random effects (cross) } \\
\hline BTN-C & -15484.68 & & & \\
\hline BNI-C & 14769.03 & & & \\
\hline MANDIRI-C & 40331.12 & & & \\
\hline \multirow[t]{3}{*}{ _BRI-C } & -39615.46 & & & \\
\hline & Effects & ication & & \\
\hline & & & S.D. & Rho \\
\hline Cross-section random & & & 3033.453 & 0.00921 \\
\hline \multicolumn{5}{|c|}{ Period fixed (dummy variables) } \\
\hline \multirow[t]{2}{*}{ Idiosyncratic random } & & & 9522.322 & 0.9079 \\
\hline & \multicolumn{3}{|c|}{ Weighted statistic } & \\
\hline r-squared & 0.954236 & Mean d & ent var & 118872.8 \\
\hline Adjusted r-squared & 0.936939 & S.D. $d$ & ent var & 80450.98 \\
\hline S.E. of regression & 20202.82 & Akaike & riterion & 22.89555 \\
\hline Sum squared resid & $5.18 \mathrm{E}+10$ & Schw: & terion & 23.77834 \\
\hline Log likelihood & -1965.809 & Hannan & c criter & 23.25357 \\
\hline f-statistic & 55.16853 & Durbin & on stat & 1.223350 \\
\hline Prob(f-statistic) & 0.000000 & & & \\
\hline
\end{tabular}

Dari persamaan regresi berganda tersebut dapat diuraikan sebagai berikut:

1) Apabila variabel modal, dana pihak ketiga, jumlah kantor cabang, tingkat bunga dan jumlah uang beredar tidak ada penambahan, maka jumlah kredit UMKM bank BUMN adalah sbesar 6.942.054 juta.

2) Apabila ada penurunan modal bank 1 juta maka jumlah kredit UMKM bank BUMN akan meingkat 40.200.900, demikian juga sebaliknya dengan tingkat elastisitas -0.114829 (kurang elastis).

3) Apabila variabel dana pihak ketiga naik 1 juta maka jumlah kredit UMKM bank BUMN akan naik 610.616; demikian jugas ebaliknya dengan tingkat elastisitas 0.869743 (kurang elastis). 
4) Apabila variabel jumlah kantor cabang bank BUMN bertambah 1 unit maka akan meningkat jumlah kredit UMKM bank BUMN 44.134.080; demikian juga sebaliknya dengan tingkat elastisitasnya 0.100184 (kurang elastis)

5) Apabila tingkat suku bunga turun $1 \%$, maka akan meningkat jumlah kredit UMKM bank BUMN sebesar 10.828.790; demikian juga sebaliknya dengan tingkat elastisitas -0.470239 (kurang elastis).

6) Apabila jumlah uang beredar meningkat 1 juta, maka jumlah kredit UMKM bank BUMN akan meningkat 39.023.116; demikian juga sebaliknya dengan tingkat elastisitas 0.106228 (kurang elastis).

2. Regresi jumlah kredit UMKM bank BUMN terhadap produk domestik bruto

Tabel 5

Pengaruh jumlah kredit UMKM bank BUMN terhdap produk domestik bruto

\begin{tabular}{|c|c|c|c|c|}
\hline \multicolumn{5}{|c|}{ Dependent variable: $Z \_1$} \\
\hline \multicolumn{5}{|c|}{ Method: least squares } \\
\hline \multicolumn{5}{|c|}{ Date: 01/29/19 time: $13: 06$} \\
\hline \multicolumn{5}{|c|}{ Sample: 1176} \\
\hline \multicolumn{5}{|c|}{ Included observations: 176} \\
\hline variable & coefficient & $\begin{array}{l}\text { Std. } \\
\text { Error }\end{array}$ & t-statistic & Prob. \\
\hline $\mathrm{C}$ & 1274014 & 77800.91 & 16.37531 & 0.0000 \\
\hline Kredit UMKM & 5.668830 & 0.542533 & 10.44882 & 0.0000 \\
\hline r-squared & 0.585545 & \multicolumn{2}{|c|}{ Mean dependent var } & 1947755 \\
\hline Adjusted r-squared & 0.582014 & \multicolumn{2}{|c|}{ S.D. dependent var } & 734694.0 \\
\hline S.E. of regression & 577558.3 & \multicolumn{2}{|c|}{ Akaike info criterion } & 29.38231 \\
\hline Sum squared resid & $5.80 \mathrm{E}+13$ & \multicolumn{2}{|c|}{ Schwarz criterion } & 29.41833 \\
\hline Log likelihood & -2583.643 & \multicolumn{2}{|c|}{ Hannan-quinn criter } & 29.39692 \\
\hline f-statistic & 109.1779 & \multicolumn{2}{|c|}{ Durbin-watson stat } & 0.220804 \\
\hline Prob(f-statistic) & 0.000000 & & & \\
\hline
\end{tabular}

Pengaruh kredit UMKM terhadap produk domestik bruto cukup kuat rsquared 0.582014 prob (f-statistic $=0.0000$ ), regresi (a) 1274014 juta coeffisien (b) 5.66830 rata-rata 1.947 .755 juta dengan standar deviasi 734.694 juta pengaruhnya signifikan. Regresi Z.1 = 1274014+5.668830. Hal ini membuktikan bahwa setiap pertambahan kredit UMKM bank BUMN 1 juta berpengaruh menaikkan produk domestik bruto 5.668 .830 hampir elastis (0.9091). 
Pengaruh Dana Pihak Ketiga, Modal Bank, Jumlah Kantor Cabang, Tingkat Suku Bunga dan Jumlah Uang Beredar

Tabel 6

Pengaruh jumlah kredit UMKM terhadap tingkat pengangguran 20062016

\begin{tabular}{|c|c|c|c|c|}
\hline \multicolumn{5}{|c|}{ Dependent variable:Z_2 } \\
\hline \multicolumn{5}{|c|}{ Method: least squares } \\
\hline \multicolumn{5}{|c|}{ Date: $12 / 28 / 18$ time: $17: 30$} \\
\hline \multicolumn{5}{|c|}{ Sample (adjusted): 2006Q1 2049Q4 } \\
\hline \multicolumn{5}{|c|}{ Included observations: 176 after adjusments } \\
\hline variable & coefficient & Std. error & t-statistic & Prob. \\
\hline $\mathrm{C}$ & 825.6549 & 19.72300 & 41.86253 & 0.0000 \\
\hline Kredit UMKM & -0.00795 & 0.000138 & -5.782332 & 0.0000 \\
\hline r-squared & 0.66185 & Mean d & endent var & 731.1364 \\
\hline Adjusted r-squared & 0.656364 & S.D. de & endent var & 159.4067 \\
\hline S.E. of regression & 146.4145 & Akaike & fo criterion & 12.82206 \\
\hline Sum squared resid & 3730076 & Schwa & criterion & 12.85809 \\
\hline Log likelihood & -1126.341 & Hannan & uinn criter & 12.83667 \\
\hline f-statistic & 33.43537 & Durbin & atson stat & 1.131326 \\
\hline Prob(f-statistic) & 0.000000 & & & \\
\hline
\end{tabular}

Pengaruh kredit UMKM bank BUMN terhadap tingkat penggunaan cukup kuat r-squared 0.661185 PROB (F-statistic $=0.0000$ ). regresi (a) 825.65479 juta coeffisien (b) -0.00795 rata-rata 731 juta dengan standar deviasi 159 juta pengaruhnya signifikan. Regresi Z.2=825.6549-0.00795 (jumlah kredit UMKM bank BUMN). Hal ini membuktikan bahwa setiap pertambahan kredit UMKM bank BUMN 1 juta (1\%) berpengaruh menurunkan tingkat pengangguran $0.00795 \%$, kurang elastis (-0.4745).

\section{B. Pembahasan}

1. Pengaruh dana pihak ketiga, modal bank, jumlah kantor cabang, tingkat bunga dan jumlah uang beredar secara simultan berpengaruh signifikan dan positif terhadap jumlah kredit UMKM bank BUMN. Hasil uji F menunjukkan faktor modal bank, dana pihak ketiga, jumlah kantor cabang, tingkat bunga dan jumlah uang beredar secara simultan berpengaruh signifikan dan positif terhadap jumlah kredit UMKM bank BUMN. Uji F dengan nilai probability sebesar 0.0000 lebih kecil -0.05 . adjust r-squared $93 \%$ sisanya $7 \%$ dipengaruhi oleh variabel-variabel lain diluar model yang diteliti. Hasil pengujian ini menunjukkan bahwa kombinasi penagruh variabel Pengaruh modal bank, dana pihak ketiga, jumlah kantor cabang, tingkat bunga dan jumlah uang beredar merupakan faktor-faktor yang berkontribusi signifikan terhadap jumlah kredit UMKM bank BUMN.

2. Pengaruh dana pihak ketiga (X2) terhaadp jumlah kredit UMKM bank BUMN. Apabila dana pihak ketiga naik 1 juta maka jumlah kredit UMKM bank BUMN akan naik 610.616; demikian juga sebalinya dengan tingkat elastisitas 0.872818 (kurang elastis). Rata-rata tingkat bunga dana pihak ketiga adalah 3\%tingkat bunga bank Indonesia yang dipersamakan dengan deposito saat ini adalah 4,75\%. Pada dasarnya mereka yang emnikmati 
fasilitas kredit UMKM pada suatu bank tertentu, juga akan menyimpan dana atau tabungannya pada bank yang bersangkutan. Hal ini berarti bahwa dengan peningkatan jumlah kredit UMKM bank BUMN juga secara tidak langsung dana pihak ketiga bank BUMN juga turut serta meningkat atau dengan kata lain pihak bank sangat diuntungkan, satu dan lain hal bahwa tingkat bunga kredit yang dibebankan kepada nasabah tinggi 19\%, dengan demikian keberlangsungan usaha bank BUMN juga ditentukan dengan meningkatnya fasilitas kredit UMKM bank BUMN, pada sisi yang lain tanpa susah payah dana pihak ketiga bank juga otomatis meningkat, dengan demikian bank BUMN agar saling menguntungkan dari sisi aktiva atau kredit UMKM mendapatkan pendapatan bunga yang tinggi dan pada sisi yang lain hal transaksi atau mutasi keuangan akan lebih banyak menggunakan jasa bank dimaksud.

3. Pengaruh modal bank (X.1) terhdap jumlah kredit UMKM bank BUMN Apabila ada penurunan modal 1 juta maka jumlah kredit UMKM bank BUMN akan meningkat 402.009; demikian juga sebaliknya dengan tingkat elastisitas -0.114829 (kurang elastis). Pada umumnya modal berpengaruh positif terhadap penjualan maupun tingkat keuntungan bagi badan usaha jasa perbankan berdasarkan kepercayaan dan image masyarakat pada umumnya, oleh karenanya faktor modal tidak menjadi pertimbangan yang berarti bagi pelanggannya. Untuk menjamin kelancaran dan keamanan usaha perbankan pemerintah mengeluarkan banyak regulasi. Fakta dilapangan bahwa para nasabah telah menyimpan dananya di bank meskipun tingkat bunga dana pihak ketiga sangan rendah, dan bagi para pengguna dana mau membayar tingkat bunga pinjaman yang tinggi. Hal ini terbukti dari rata-rata tingkat suku bunga dana pihak ketiga $3 \%$ atau BI rate saat ini adalah $4,75 \%$ pertahun, sementara tingkat suku bunga kredit UMKM rata-rata $10,86 \%$ atau terdapat selisih bunga sebesar 6,11\%. Meskipun diluar biaya bunga dana pihak ketiga masih ada biaya lainnya, misalnya biaya operasional, tentunya selisih tingkat bunga yang tinggi tersebut sangat menguntungkan bisnis usaha perbankan, dengan bekerja biasa-biasa saja tingkat pendapatan atau keuntungan bank sudah memadai dan dapat memberikan kontribusi pajak, corporate social responsibility dan dividen bagi pemegang saham.

Dalam kasus penambahan modal bank BUMN ini menjadi kontradiktif terhadap teori modal pada badan usaha lainnya, selain selisih bunga dana pihak ketiga dan bunga kredit sangat besar, juga terdiri karena:

a. Pertambahan modal (equity) pertumbuhannya lebih besar dari pertumbuhan kredit khusunya kredit UMKM, akumulasi modal terus bertambah besar

b. Secara internasional CAR cukup $8 \%$. Dibanyak negara dalam praktek misalnya tiongkok tingkat bunga kredit berkisar 3\%-5\% dan CAR ratarata $11 \%$ atau rata-arat lebih tinggi 3\% dari ketentuan regulasi 
internasional. Di Indonesia hinggas aatt ini bank BUMN berkisar 16\% hingga $21 \%$ atau kelebihan sebesar $7 \%$ hingga $12 \%$; dengan kata lain rata-rata kelebihan $100 \%$ dari regulasi, hal ini berarti terjadi inefisiensi penggunaan modal bank

c. Dalam lima tahun terakhir CAR bank BUMN cenderung meningkat dimana pada tahun 2012 sebesar 16,75\% terus meningkat menjadi $20,25 \%$ pada tahun 2016 , lebih tinggi dari $16,01 \%$ turun menjadi $15,44 \%$ pada tahun 2016.

d. Secara teoritis dan faktual jika kita menggunakan teori manajemen keuangan tentang struktur utang atau teori leverage, jika biaya modal asing atau utang jauh lebih kecil daripada tingkat keuntungan akan lebih efisien atau earning persharenya lebih tinggi menggunakan utang atau dana pihak ketiga daripada menggunakan modal sendiri.

Berdasaekan pembahsan tersebut diatas, agar penggunaan modal bank BUMN lebih optimal disarankan:

1) Kelebihan modal tersebut dilakukan ekspansi kredit UMKM, satu dan lain hal bahwa kredit macet rata-raat perbankan 3,4\%, standar NPL bank dikategorikan termasuk yang sehat oleh bank Indonesia NPL sebesar 5\%

2) Modal dana pihak ketiga pada dasarnya saling melengkapi atau bersifat komplimenter, dana pihak ketiga karena biaya dana ini murah an harus diupayakan terus meningkat, untuk optimalisasi pengelolaan modal, maka yang harus dikurangi adalah akumulasi jumlah modal dimanfaatkan sebesar-besarnya untuk peningkatan kredit UMKM sehingga CAR menjadi turun mendekati CAR minimum $8 \%$ sehingga penggunaan modal akan lebih efektif dan efisien.

3) Cara lainnya dalam rangka optimalisasi penggunaan modal bank BUMN dengan membeli kembali saham yang beredar di pasar sekunder atau di bursa efek Indonesia.

4) Pemerintah menarik kelebihan modal bank BUMN sebagai modal dasar pendirian bank BUMN yang baru; satu dan lain hal peranan bank BUMN masih kecil jika dibandingkan peran bank asing dan bang swasta lainnya.

5) Pemerintah menerbitkan regulasi baru tentang CAR meksimum bank BUMN, misalnya $15 \%$, dengan demikian kelebihan CAR atau modal dimaksud disalurkan dalam bentuk kredit.

4. Pengaruh jumlah kantor cabang bank BUMN (x3) terhadap jumlah kredit UMKM bank BUMN

Apabila jumlah kantor cabang bank BUMN bertambah 1 unit maka akan meningkatkan jumlah kredit UMKM bank BUMN 31.479.800; demikian juga sebaliknya dengan tingkat elastisitas 0.100184 (kurang elastis). 
Dilihat dari tingkat pertumbuhan kantor cabang bank BUMN dalam 5 tahun terakhir terjadi penurunan dari 13,97\% tahun 2012 turun 3,18\% pada tahun 2016; teknologi saat ini terus berkembang maju, dapat memberikan kemudahan dan lebih efektif dan effisien operasional perbankan. Teknologi dapat menggantikan tenaga manusia khususnya kegiatan back office berkaitan dengan birokrasi dan pencatatan transaksi keuangan bank maupun nasabah bank sangat dimudahkan oleh teknologi dan komputerisasi. Dari sisi penghimpunan dana pihak ketiga peranan komputerisasi dan ATM bersama sangat besar manfaatnya, emngingat besarnya risiko kredit macet dan moral hazard, tentunya penyebaran dan keberadaan kantor cabang bank diperlukan dekat dengan para penggunanya.

Keberadaan sebuah kantor cabang erat kaitannya dengan penambahan biaya operasional dan logistik. Mengingat bahwa kantor cabang bank secara hirarkis terdiri dari kantor pusat, wilayah, cabang, cabang pembantu dan kantor kas dengan fungsi dan tugas yang berbeda sehingga dalam pendirian sebuah kantor cabank bank diperlukan perhitungan yang matang. Terkait dengan fsilitas kredit mikro, kecil dan menengah keberadaan sebuah kantor cabang sebagai pengawas dan pembina usaha debitur, keberadaan kantor cabang pembantu sangat diperlukan bagi kelangsungan usaha bank dan kelancaran pembayaran kredit debitur.

Berdasarakan fakta dilapangan khusus para debitur kredit mikro dan kecil sangat enggan mendatangi sebuah kantor cabang yang besar dengan alsan:

a. Fasilitas kredit yang mereka butuhkan relatif kecil-kecil, untuk memasuki suatu kantor cabang yang besar dan megah merasa sungkan

b. Pada umumnya mereka bekerja mandiri, dalam prakteknya pemberian fasilitas kredit memerlukan banyak syarat-syarat yang bagi mereka hal itu merepotkan.

c. Belum lagi dengan bolak-balik mengrus berbagai persyaratan administrasi ijin, akan mengganggu kegiatan usaha mereka atau dengan kata lain selama mereka mondar-mandir mereka menutup usahnya.

Mengingat berbagai masalah tersebut diatas kadangkala mereka tidak melihat tingkat bunga kredit bank yang murah saja, tetapi lebih kepada kemudahan mereka mendapatkan pinjaman kredit, banyak diantara mereka lebih memilih yang paling mudah walaupun mahal dengan pinjam kepada rentenir. Oleh karenanya keberadaan kantor kas bank BUMN sangat diperlukan, dan agar saling menguntungkan bagi bank dan para pengusaha kecil bank BUMN proaktif mendatangi para pengusaha kecil yang dimaksud.

5. Pengaruh tingkat bunga (X4) terhadap jumlah kredit UMKM bank BUMN Apabila tingkat bunga turun $1 \%$ maka akan meningkatkan kredit UMKM bank BUMN sebesar 10.828.790 demikian juga sebaliknya dengan 
tingkat elastisitas -0.470239 (kurang elastis). Tingkat bunga ini relatif besar pengaruhnya jika dibandingkan variabel lainnya, namun tingkat bunga mempunyai arti yang sangat strategis bagi para pihak, perbankan, masyarakat penyimpan dananya di bank, debitur dan pemerintah.

Bank Indonesia terkait dengan kebijakan moneter erat kaitannya dengan tingkat bunga kredit UMKM seperi saat ini, berpengaruh terhadap harga jual pokok. Ini pada akhirnya menambah daftar "linkaran setan" yang membelit UMKM. Akibatnya, sektor usaha ini menjadi sulit berkembang , bahkan sulit bersaing menghadapi pasar internasional yang di negara lain tingkat bunga jauh lebih rendah.

Kebijakan subsidi bunga, pemerintah menetapkan suku bunga UMKM mikro, kecil dan UMKM mikro retail masing-masing dari 22\% dan $14 \%$ menjadi $12 \%$ pada tahun 2015 , kemudian menjadi $9 \%$ pada tahun 2016 dan 7\% pada tahun 2017. Negosiasi yang dilakukan pemerintah dengan pihak perbankan menyepakati bahwa tingkat suku bunga pasar untuk KUR mikro adalah $19 \%$, sedangkan untuk KUR retail 15\%. Dengan demikian, untuk KUR mikro subsidi bunga yang ditanggung pemerintah adalah $7 \%$ pada tahun 2015 dan 10\% pada tahun 2016. Sementara itu tanggungan subsidi pemerintah untuk KUR retail adalah 3\% pada tahun 2015 dan 5,5\% pada tahun 2016. Penurunan suku bunga UMKM bisa menimbulkan dua akibat. Di satu sisi, mendorong iklim kompetisi yang lebih fair di pasar kredit UMKM. Perbankan yang tidak mau melakukan inovasi akan kalah dan tersisi dalam persaingan di pasar kredit UMKM. Hal ini akan berdampak secara positif terhadap UMKM untuk mendapat pinjaman suku bunga yang lebih murah. Di sisi lain, penurunan suku bunga juga bisa menimbulkan crowding effect terhadap kredit-kredit UMKM yang sifatnya lebih komersial. Hal positif lainnya terkait dengan suku bunga bank dan UMKM dimana perbankan yang telah berusaha membantu UMKM dengan pemberian kredit dan pembinaan manajemen UMKM. Hal ini membentuk hubungan saling menguntungkan antara kedua belah pihak sehingga UMKM tidak perlu lagi meminjam uang dari rentenir.

6. Pengaruh jumlah uang beredar (X5) terhadap kredit UMKM bank BUMN

Apabila jumlah uang beredar meningkat 1 juta, maka jumlah kredit UMKM bank BUMN akan meningkat 39.023.116; demikian juga sebaliknya dengan tingkat elastisitas 0.106228 (kurang elastis). Dari tahun ke tahun secara nominal terus meningkat, namun dilihat dari persentasi pertumbuhan dalam 5 tahun terakhir terjdai pelambatan dari 21,05\% tahun 2012 terus menurun menjadi 10,17\% tahun 2016. Secara empiris dalam jangka panjang uang diperlukan untuk pertukaran dan pertumbuhan ekonomi, pda sisi lain mempunyai pengaruh yang sangat signifikan menimbulkan inflasi, oleh karena peredaran uang harus dikelola secara baik dan sesuai kebutuhan dalam perekonomian secara baik dan sesuai kebutuhan dalam perekonomian suatu 
negara. Pertumbuhan jumlah penduduk dan peningkatan pendapatan masyarakat meskipun akan menimbulkan inflasi yang diikuti dengan kenaikan harga-harga barang dan jasa, hal tersebut dapat diartikan pula selama inflasi terkendali dibawah dua digit atau dibawah $10 \%$ relatif masih aman. Hal ini merupakan peluang bisnis yang ditunggu-tunggu oleh mereka yang terlibat didalam bisnis termasuk didalamnya UMKM, dengan adanya kenaikan harga dan jasa serta meningkatnya pendapatan masyarakat mempunyai daya tarik yang tinggi untuk memasuki usaha baru dan bagi mereka yang sudah berbisnis cenderung akan memperluas usaha mereka karena ada pengharapan pendapatan akan meningkat.

Dengan meningkatnya jumlah uang beredar, akan meningkatkan pendapatan masyarakat dan pendapatan para pengusaha UMKM pada akhirnya akan berdampak pada meningkatnya pendapatan pemerintah dari sektor pajak yang selanjutnya dapat meningkatkan APBN, pertumbuhan ekonomi nasional dan berlanjutnya pembangunan nasional.

7. Pengaruh jumlah kredit UMKM bank BUMN terhadap produk domestik bruto

Hasil penelitian ini membuktukan bahwa setiap pertambahan jumlah kredit UMKM bank BUMN 1 juta berpengaruh menaikkan produk domestik bruto 5.668.830; hampir elastis (0.9091).

Adapun porsi masing-masing bank penyaluran kredit UMKM perbankan berdasarkan data tahun 2016: bank BUMN 17,32\%, BUSN 44\%, Bank asing 25,23\% dan BPD 13,45\%. Fakta ini membuktikan bahwa dari 124 bank BUMN porsi pembiayaan UMKM $(17,32)$ menempati urutan ketiga setelah bank umum swasta nasional dan asing, namun lebih besar dari porsi BPD hanya sebesar 13,45\%. Bank BUMN sebagai bank pemerintah lebih meningkatkan lagi pertumbuhan UMKM nya sehingga dapat mengejar bank asing dan bank swasta nasional. Produk domestik bruto dapat digunakan untuk mempelajari perekonomian dari waktu ke waktu atau untuk membandingkan beberapa perekonomian pada suatu saat. Disamping itu juga dapat digunakan untuk menentukan besarnya kontribusi berbagai sektor perekonomian terhadap pendapatan nasional. Indonesia turut berkomitmen dalam rangka peningkatan produk domestik bruto erat kaitannya dengan inklusif keuangan telah menjadi isu ekonomi dunia, sejak menjadi kesepakatan KTT G-20 pada tahun 2009 silam, para pemimpin negara terus memperbincangkan masalah inklusif keuangan sebagai motor sustanibility pertumbuhan ekonomi dan pengentasan kemiskinan. Adapun implementasinya saat ini adalah keterpihakan kepada UMKM agar terus bertambah banyak dan terjadi kenaikan kelas dari pengusaha mikro menjadi kecil, kecil menjadi usaha menengah. Melalui fasilits kredit UMKM jumlah pengusaha Indonesia terus bertambah untuk mengejar ketertinggalan, indonesai saat ini hanya $1,65 \%$ dari jumlah penduduk. 
Bank BUMN memiliki potensi yang sangat besar untuk dikembangkan dan menjadi lokomotif pembangunan ekonomi karena unggul dalam hal penyediaan layanan, keuangan dana pihak ketiga dan kredit, memiliki tingkat kepercayaan yang sangat tinggi di masyarakat, kuat dalam menelolan risiko dan produk dana pihak ketiga masyarakat dijamin oleh lembaga penjamin simpanan (LPS) serta jaringannya sangat tersebar dan luas, sehingga dalam hal ini pemerintah harus berupaya semaksimal mungkin mengoptimalkan bank BUMN ini sebagai agent of development.

Pemerintah harus lebih mendorong pertumbuhan UMKM, kontribusi UMKM dalam perekonomian Indonesia masih belum optimal dibandingkan dengan potensi yang ada apalagi jika kita bandingkan dengan negara lain, jumlah UMKM yang tersebar di Indonesia masih kurang dari 30\% dari total UMKM.

Berdasarkan hasil penelitian ini dapat diketahui bahwa peran bank BUMN untuk meningkatkan produk domestik bruto sangat strategis, tidak hanya menguntungkan bagi bank BUMN terlebih lagi bagi pemerintah terkait dengan efek multi player effect dimana pertambahan jumlah kredit UMKM berpengaruh signifikan meningkatkan produk domestik bruto. Dalam hal ini pemerintah sebagai pemilik mayoritas saham bank BUMN, perlu memperhatikan pengaruh multy player effect, daripada sekunder mengharapkan deviden dan coorparate social responsibility (CSR) saja dan penerimaan pajak secara nasional dan pertumbuhan ekonomi serta pemerataan pembangunan di seluruh nusantara.

8. Pengaruh jumlah kredit UMKM bank BUMN terhadap tingkat pengangguran

Penelitian ini membuktikan bahwa setiap pertambahan kredit UMKM bank BUMN 1 juta (1\%) berpengaruh menurunkan tingkat pengangguran $0.00795 \%$ kurang elastis (-0.4745). Data menunjuk bahwa tingkat pengangguran Indonesia dalam 11 tahun terakhir cenderung menurun dari 10,45\% pada tahun 2006 terus menurun menjadi 5,33\% pada tahun 2016; namun secara kualitas penurunan dalam 5 tahun relatif mengecil bahkan dalam tahun 2013 terjadi kenaikan tingkat pengangguran dari 6,37\% (2012) menjadi 6,70\% (2013).

Pengangguran dan jumlah kredit UMKM bank BUMN, berdasarkan kementerian koperasi dan UMK-BPS 2015 diketahui bahwa faktor yang paling menghambat adalah permodalan $51,09 \%$, pemasaran $34,72 \%$, bahan baku $8,59 \%$, ketenaga kerjaan $1,09 \%$, distribusi transportasi $0,22 \%$, lainnya $3,91 \%$, fakta ini menyatakan bahwa kendala utama dan yang paling kritis bagi pengurangan tingkat pengangguran melalui pertumbuhan UMKM adalah ketiadaan atau kekurangan modal atau peningkatan fasilitas kredit perbankan. Pembiayaan mikro dipandang cukup efektif dalam meningkatkan kapasitas keuangan masyarakat miskin karena lebih fleksibilitas, jangka waktu pendek, agunan yang fleksibel (seperti sosial kolateral) dapat dilakukan untuk usaha- 
usaha mikro berkelompok mampu menciptakan insentif yang dinamis, meningkatkan kapasitas pembiayaan, sistem cicilan yang teratur, serta alternatif agunan.

\section{Kesimpulan}

Secara simultan dan parsial variabel dana pihak ketiga, modal bank, jumlah kantor cabang, tingkat bunga, jumlah uang beredar berpengaruh secara signifikan terhadap jumlah kredit UMKM bank BUMN. Secara umum badan usaha bisnis variabel modal berpengaruh positif terhadap fasilita s kredit, dalam penelitian ini modal bank pengaruhnya negatif karena terjadi kelebihan modal atau penggunaan modal tidak efisien.

Dana pihak ketiga terus meningkat merupakan kabar baik bagi usaha perbankan, karena tidak dipungkiri bahwa maju mundurnya usaha perbankan sangat tergantung tersedianya dana pihak ketiga, satu dan lain hal tingkat bunga dana pihak ketiga relatif sangat rendah jika dibandingkan dengan tingkat bunga kredit.

Secara nominal jumlah kredit UMKM bank BUMN terus meningkat, namun secara riel pertumbuhannya atau persentasinya dalam 5 tahun terakhir porsinya terus menurun pada tahun 2006 persentasi kredit UMKM 72,62\% dari total kredit bank BUMN, terus menyusut hingga 51,01\% pada tahun 2016. Jika dilihat dari tingkat pertumbuhan jumlah kredit UMKM bank BUMN dalam 5 tahun terakhir 2012 tingkat pertumbuhan $15,35 \%$ terus menurun hingga menjadi $10,21 \%$ tahun 2016 . Jumlah kantor cabang merupakan ujung tombak dalam melayani fasilitas kredit UMKM bank BUMN, dilihat dari tingkat pertumbuhan kantor cabang bank BUMN dalam 5 tahun terakhir terjadi penurunan dari 13,97\% tahun 2012 turun menjadi 3,18\% pada tahun 2016. Tingkat bunga dalam 11 tahun terakhir mengalami naik dan turun, namun trendnya cenderung menurun merupakan kabar baik bagi perbankan dan debitur UMKM. 


\section{BIBLIOGRAFI}

Dombusch, Rudiger. (1997). How Real is US Prosperity?" Column reprinted in World Economic Laboratory Columns, MIT.

Ehrenberg, Ronald G., \& Smith, Robert S. (2000). Modern labor economics: Theory and policy. Addison-Wesley. New York.

Hudson, John, Williams, Colin, Orviska, Marta, \& Nadin, Sara. (2012). Evaluating the impact of the informal economy on businesses in South East Europe: some lessons from the 2009 World Bank Enterprise Survey. South East European Journal of Economics and Business, 7(1), 99-110.

Latumaerissa, Julius R. (2014). Manajemen bank umum. Jakarta: Mitra Wacana Media.

Manihuruk, Christianus. (2018). Pengaruh Modal Bank, Alokasi Kredit Dana Pihak Ketiga, dan Jumlah Kantor Cabang Bank BUMN Persero terhadap Jumlah Kredit Usaha Kecil dan Implikasinya pada Tingkat Pengangguran. JURNAL EKONOMI, 20(3), 316-335.

Meier, Petra S., Barrowclough, Christine, \& Donmall, Michael C. (2005). The role of the therapeutic alliance in the treatment of substance misuse: a critical review of the literature. Addiction, 100(3), 304-316.

Nopirin, M. A. (2012). Analisis Faktor-Faktor Yang Mempengaruhi Ekspor Indonesia Tahun 1988-2008. [Yogyakarta]: Universitas Gadjah Mada.

Nye, Joseph S. (2013). What China and Russia don't get about soft power. Foreign Policy, 29(10).

Simarmata, Parihutantua. (2017). Hukum Zona Ekonomi Eksklusif dan Hak Indonesia Menurut Undang-Undang RI Nomor 5 Tahun 1983. Syntax Literate; Jurnal Ilmiah Indonesia, 2(2), 108-123.

Suryana, Yuyus, \& Bayu, Kartib. (2012). Kewirausahaan: Pendekatan Karakteristik Wirausahawan Sukses Ed. 2. Kencana.

Todaro, Michael P. (2000). Economic Development. New York University. New York. 